\title{
Closing the Gap: some unsettling assumptions
}

A remote region case study

\author{
Ann Ingamells \\ Griffith University
}

\begin{abstract}
Australian governments are committed to closing the gap between Indigenous and other Australians, yet progress is slow. This paper draws links between these policy efforts and a study of a remote shire in Western Queensland where indicators suggest better than usual socioeconomic outcomes for Aboriginal people. The study conducted over a three year period, and with significant input from Aboriginal people, examines the pathway through which these outcomes have been achieved. Local accounts suggest relations between long term families of both cultures have been a significant factor and are the outcome of an iterative dynamic between people, place and resources, that has a long history, and path dependence. Despite almost full engagement of Aboriginal people in employment over the past 100 years however, indicators do not yet converge, suggesting policy targets are ambitious. The persistent 'gap' may be the effect of insistence on making equality conditional on acceptance of settler norms, at significant cost to the lived expression of Aboriginal culture. Whilst this community has managed these tensions, nevertheless their experiences imply that access to community services in remote areas, rather than being a right, is precariously dependent on the vicissitudes of relationship, and these may often depend on the choices Aboriginal people make in response to assimilatory pressures.
\end{abstract}

Keywords: 'Closing the Gap', remote settlements, Aboriginal, Indigenous, intervention, governmentality

The Australian Government's vision of a socially inclusive society is one in which all Australians feel valued and have the opportunity to participate fully in the life of our society. Achieving this vision means that all Australians will have the resources, opportunities and capability to learn, work, engage in the community and have a voice. (Commonwealth of Australia, 2010) 
In 2002 federal, state and territory governments, acting through the Council of Australian Governments (COAG), agreed to work together to 'close the gap' between Indigenous and other Australians (SCRGSP, 2009). Seven years later, Gary Banks (2009), chairman of the Productivity Commission, which publishes the bi-annual reports on the progress in Overcoming Indigenous Disadvantage (OID), expressed concern that so little progress had been made. His concern was echoed by Prime Minister, Kevin Rudd (2009). In the light of this espoused commitment to 'closing the gap' across Australia, and the intractability of disadvantage, especially in remote Australia, it may be instructive to consider what can be learned from remote communities where Aboriginal people ${ }^{1}$ are doing comparatively well on conventional indicators and are enjoying significant levels of inclusion. Recognising the uniqueness of each settlement and the different histories and demographics of each state and territory, one case study cannot be taken as evidence, but the paper proceeds on the assumption that juxtaposing rich description of lifeworlds with policy discourse may contribute to understandings about the scope, timeframes and strategies of 'Closing the Gap'.

There is less than usual stratification on some dimensions in the case study site, however it will be no surprise that here, as elsewhere across Australia, the tensions of two cultures coming together were long ago resolved in favour of the settler culture. Aboriginal people enjoy their present social and economic status, but recognize it is an effect of living within settler norms (and bearing silently, the subsequent costs to their own culture). It would be easy to critique local politics on that score, yet it is hard to point to any place where settler culture has not overshadowed Aboriginal and Torres Strait Islander cultural symbolics. Despite significant academic attention, this question barely disturbs the policy domain. The opening quote of this paper was chosen from the Commonwealth's Social Inclusion website, specifically to hold within the discussion, this underlying but forceful linking of entitlements, citizenship and values conformity within a vision of one Australia.

\section{The Research Process}

Between 2006 and 2009 Desert Knowledge Cooperative Research Centre (CRC) undertook a study of the sustainability of remote desert settlements. That research, still to be published in its entirety, focused social, political and economic sustainability across five sites in and around the central desert. This paper draws on a small part of it, a study of one shire on the Queensland edge of the Simpson Desert. The emphasis of this paper is not settlement sustainability, but rather one significant theme that emerged in the process of building that case study: namely, a combination of local accounts and demographic statistics point to some better socioeconomic outcomes for Aboriginal people than is usually the case across remote Australia.

The research team (the author together with Aboriginal colleague, Colleen Wall) visited Diamantina Shire many times over a three year period. We interviewed seventy people of the three hundred people of the shire, including residents of both cultural groups, business owners, professionals and council representatives. We provided summaries of data, discussed interpretations and facilitated some conversations about the relation between local people's views and other sources of data (for example, Australian Bureau of Statistics data). The interviews provided an initial means of engaging the community and led to us working alongside Aboriginal people, local government and a local social organisation on different projects of each. A theme explored in more depth at the request of the Wangkangurru and Yarluyandi 
Elders and local government was the development of relations between Aboriginal and settler families in the Shire. This paper draws on discussions with community members around that theme.

From multiple conversations over a lengthy period of time, a large amount of data was collated. The researchers identified themes pertinent to this paper and local people decided on which best reflected their emphases. Because of their interest in the topic, Aboriginal people have influenced this prioritizing more than other community members. For them it was important to acknowledge the good relations and achievements, yet not gloss over the costs. This paper then reflects a community conversation up to a particular point, recognizing that the conversation is far from complete or over.

\section{Policy and its Critics}

The Commonwealth and State governments through the Council of Australian Governments (COAG) have committed to end Indigenous disadvantage. This requires all levels of government to create programs to 'close the gap'. The Productivity Commission is tasked with tracking progress and reporting on outcomes. More recently, the Labor Government established a Social Inclusion Board to advise on priorities in addressing exclusion across all groups in Australia.

In both of these policy domains there is a similarity of approach. They each rely on detailed use of statistics to identify 'gaps' and track progress. Whilst statistics are necessary to a reform process (Rowse, 2006) over emphasizing them effectively constructs: as the problem, the group whose details are to be measured; the desired change as change in that group; and, by implication, failure to achieve outcomes, as that group's recalcitrance. This is what Rose (1999) following Foucault $(1984,1991)$ calls a disciplinary strategy. The group is named, separated out, mapped and targeted for intervention. Failure to self-govern according to dominant group norms attracts government and community censure. The structural dimensions, the policy inadequacies, the ethnocentricity and historical legacy are obscured by the direction of the policy gaze. Neither of these policy domains has a clearly or theoretically articulated strategy for change. Apart from service inputs, and partnerships with industry to generate employment, it is unclear how the shift from A to B will occur. As Pholi, Black \& Richards (2009) argue, there is nothing new about the ideological heritage of the approach, it is guided by the same individualistic norms and assumptions as have been the cause of exclusion.

For many years policy commentators have been arguing that strategies are needed that take into account historical legacy, reflexivity about cultural difference, diversity of circumstance, remote demographics and impacts of macroeconomic change (Altman, Biddle \& Hunter, 2005, 2008; Rowse, 2006). Technical instrumentalism will not close the gap. Indeed projections calculated by Altman et al. (2008) suggest that statistical convergence could take as much as $100+$ years on several indicators. So, whilst there is currently popular support for 'Closing the Gap', failure to reach targets, for example of ending health inequality by 2030, is likely to produce impatience and negativity, directed more at Aboriginal and Torres Strait people, than at government.

A growing number of those who support change are questioning both the agenda and the policy processes. Altman (2009) has summarised these critiques as concerned with the antiquated paradigm of top down development and associated 
denial of Indigenous agency; the representation of Indigenous difference as the problem to be fixed; the failure to value different cultural and social norms; the failure to address the structural components of disadvantage; and ignoring the historical legacy of the problem. Altman's central critique, however, is the enduring failure on government part to match its universalist emphasis on equality and citizenship with a policy discourse that values diverse lifeworlds.

There has been support from Aboriginal and Torres Strait Islander People for 'Closing the Gap' insofar as it promises services that should long ago have been available. Some argue for even shorter timeframes for change (Dodson, 2009; Pearson, 2009). Others remind that holding together the fabric of their cultural, spiritual, social, economic and intellectual lives, entails a range of considerations that are not necessarily evident to policy makers (Behrendt, 2008; Watson, 2009). Whilst insistent that their rights as citizens be upheld, and matched with associated entitlements, Aboriginal and Torres Strait Islander people argue they need to be actively engaged, not just at the policy level, but also in the integration of those entitlements and rights into their societal systems (Watson, 2009).

Dillon \& Westbury (2007) argue that the problem of government disengagement from responsibility for remote areas is wider than Indigenous policy. Whatever the policies, governments are rarely able to operationalise them sustainably and successfully in remote areas (Stafford Smith, 2008). Sparsely populated terrain across inland Australia, staff capability and retention issues, the urban mental models of policy makers and the priorities of urban political constituencies, combine to ensure that remote areas get a poor deal (Stafford Smith, Moran \& Seemann, 2008). Both ethnocentricity and urban-centricity then hamper the policy process.

\section{Diamantina Shire: the Case Study Site}

There are two settlements in the vast $94,832 \mathrm{~km}^{2}$ of Diamantina Shire. The population is around 300 people but swells to as much as six times that number in the winter tourist season. As indicated in Table 1, Aboriginal people constitute $27.9 \%$ of the population. This is much smaller than in the Northern Territory, but larger than neighbouring western shires, including the mining centre of Mt Isa.

Table 1: Aboriginal and Torres Strait Island People as Percentage of Population

\begin{tabular}{ccccccl}
\hline Diamantina & Barcoo & Boulia & Winton & Mt Isa & Qld & Aus \\
\hline $27.9 \%$ & $6.7 \%$ & $24.4 \%$ & $9.4 \%$ & $16.6 \%$ & $3.6 \%$ & $2.3 \%$ \\
\hline
\end{tabular}

Source: Basic data collated from (2007) Australian Bureau of Statistics, 2006 Census, Quickstats.

There are many small towns in Western Queensland where a settler and smaller Aboriginal population live side by side. The economies of these towns are settler dominated, and this is the case in Diamantina Shire. It is rare though that both cultural groups are fully engaged in the economy. This is one of the things that sets Diamantina Shire apart. A history of full employment, combined with an ethic, articulated across the community, that everyone should work, has had a shaping effect on the town's socioeconomic profile. In Diamantina Shire, people work together, volunteer together and socialise together. For the past two decades there has been Aboriginal representation on Council and Aboriginal people are as keen as anyone 
else to have their voices heard on local issues. Economic participation and social inclusion are high.

Table 2 suggests similarity on some indicators between Aboriginal people and other residents in Diamantina Shire, whereas neighbouring Boulia Shire and Queensland as a whole show the kinds of gaps in age, income and household size that indicate stratification.

Table 2: Selected Medians by Aboriginal and Torres Strait Island Status and Place

\begin{tabular}{lcccccc}
\hline & \multicolumn{2}{c}{ Diamantina } & \multicolumn{2}{c}{ Boulia } & \multicolumn{2}{c}{ Queensland } \\
\hline Median Age & Aboriginal & Other & Aboriginal & Other & Aboriginal & Other \\
Median & 35 & 34 & 24 & 37 & 20 & 36 \\
$\begin{array}{l}\text { Individual } \\
\text { Wkly Income }\end{array}$ & 553 & 613 & 226 & 615 & 318 & 481 \\
$\begin{array}{l}\text { Household } \\
\text { Size }\end{array}$ & 2.6 & 2.3 & 3.6 & 2.6 & 3.5 & 2.6 \\
\hline
\end{tabular}

Source: Basic data collated from (2008), Australian Bureau of Statistics, 2006 Census, Community Profiles.

Twenty percent of Aboriginal people over 15 years of age in Diamantina Shire earn over $\$ 1000$ per week, which is significant for a non-mining, remote town. By comparison, there are no Aboriginal people in neighbouring shires of Boulia and Barcoo who earn $\$ 1000$ per week. Many remote shires have high unemployment and it is by the efforts and commitments of local people working with their local government that unemployment and dependence on income support are low in Diamantina Shire. Even with the recession in 2009, Diamantina Shire unemployment rate was $2 \%$.

The education gap still exists, but is slowly closing. Primary schools in each settlement have between 9 and 14 pupils, and all children leave home to board at high school. There is an increasing post school trend of Aboriginal young people returning to their settlements after high school to seek qualification and credentials locally. Settler young people are more likely to leave for university. Health data is sketchy for small population areas, but, whilst the usual illnesses suffered by Aboriginal populations are present, the infant mortality rate is nil across both population groups. On suicide data, Public Health Information Unit (2006) places Diamantina in the lowest category across the nation. Altman et al. (2008) suggest percentage of population over 55 years is a reasonable indicator of comparative health. Current ABS data shows $9 \%$ of the Aboriginal population, whereas $22.7 \%$ of the settler population, are over 55 years. This may reflect that as Aboriginal people age they are more likely to have illnesses that require them to leave town to be closer to hospitals, but it also indicates the lengthy timeframes required to close gaps in health outcomes, even with full economic participation.

For a desert clime, Diamantina is rich cattle fattening country. Grasses are due to regular floods from the gulf moving south to Lake Eyre. Cattle fattened in Diamantina however generally go to market from holding stations elsewhere, so whilst the industry contributes significantly to the national economy, this does not 
necessarily show up as economic output of the shire. The majority of cattle stations are owned by large companies that operate across several states or family owned operations that operate across state borders. Few have a policy of employing or procuring locally. In fact, the benefits to the local economy through the cattle industry seem to be few, whereas exports from the area do benefit the national economy. Similarly, there is a small amount of mining, which neither employs nor spends locally (Ingamells, Holcombe \& Buultjens, 2010). Despite the fact that local resources flow out rather than into the local economy, the people of this community, through Council, have generated jobs for everyone. This will be covered shortly.

It is hard to imagine a sphere of life in this shire that is not in some way indebted to local government. Over 150 years, the council has established itself as a strategic and administrative body that has the support of its people. Education and policing are the only two areas where state government provision can operate without significant input from local government. Health and housing draw on a range of external funding, but council provides the infrastructure, raises extra funds and generally makes them work locally. Reliability of physical infrastructure falls largely to council. Council is proactive in terms of social infrastructure and community development, assisting with the maintenance of social groups, adding energy to volunteer groups and holding continuity on a calendar of sporting and social events. There is no private real estate market in small remote settlements, no land developer, no rental agency, few private landlords, no funeral director, no after school care, no home repairs business, no hairdresser and no hardware shop. Yet, local people have ways of getting things done and council is often instrumental in this. It is facilitator of local activity around local need, joiner of dots between fragmented services and local infrastructure, and advocate and lobbyist of external agencies. Without the strategic long-term focus of an active and capable local body, these remote settlements would lose their connection to contemporary society. Council approaches these tasks with urgency, because if population numbers fall, a cascade can happen until no services are viable.

The centralized, urbanized structure of Australian political institutions serves the interior of Australia poorly (remoteFocus, 2008). It is well recognized across practice and academic domains that more emphasis needs to be given to building capability at the local governance level, including more constitutional power to local government. Subsidiarity between levels of government needs to be predicated on the specific conditions of remote living (remoteFocus, 2008; Smith \& Hunt, 2005). A stronger regulatory framework to ensure economic flows to the local from exploitation of local stocks would also be helpful. Services are vital, but alone are insufficient to close the gap.

The relevance of this picture of Diamantina Shire, is that it illustrates services do not work sustainably in remote areas unless there is a strategic entity locally able to make them work. How well Aboriginal and Torres Strait Islander people fare in remote areas will depend on their relations to this local entity. The next two sections, discuss some of the history of Diamantina Shire to substantiate the interrelatedness of Aboriginal agency, path dependency and subsidiarity as they relate to contemporary achievements.

\section{Relationship, Respect and Economy}

Western Queensland, as elsewhere across Australia, has a shameful colonial past. Aboriginal land was taken, cultural practices and economies broken up. People were 
sent away into reserves, fled, or were killed (Lukin Watson, 1998, Nolan, 2003). Through these processes settler land tenure and Aboriginal economic dependence on settlers was established. On the stations Aboriginal people received rations and maybe a small wage. Meanwhile, settler families and cattle corporations generated significant wealth. When compensation for stolen wages was introduced, some people were eligible but others found there were no records to back their claims.

Reflecting on their history, Aboriginal people recall the station owners who treated them with respect (and those who did not). They recall with pleasure evenings by the campfire when station owners and Aboriginal families enjoyed social company whilst children played together. There are other kinds of memories too - such as shame of being treated differently all those years ago in school, of being sent outside whilst other workers ate with station managers, of being kept on the doorstep and not invited in. The emphases vary according to different individuals and the different station owners they worked for. Yet families of the community learned to respect and appreciate each other. The settler families speak with respect for Aboriginal contribution to the stations, their skill and horsemanship and their role in community.

McGrath (1987) writing about Central Australia, points out that Aboriginal people on the pastoral stations often felt themselves to be in possession of their own land, looking after it and performing cultural responsibilities. This suited the pastoralists, who gained labour at a cost the station could afford, and it suited Aboriginal people. It is not that settler families of this locality had an enlightened view of culture. One respondent in our research said: ' what is there to apologise for, it was tough for everyone - no-one was worse or better treated than anyone else'. Another reflected: 'we have always tried to kind of relate to person rather than culture'. To have respect for person seemed a safer way to avoid discrimination and racism than to negotiate the complicated business of culture or prior ownership of land. Yet, this respect for persons was enough to provide the context within which a small number of families made decisions to live in the township and live in a way that would evoke respect from certain settler families. Older adults recall their parents instilling respect for settler families. This must be emphasised-respect, relationship and economic participation were interrelated and interdependent and were the basis for, and outcome of, Aboriginal people accepting settler norms.

Rowse (2005, p. 55) links respect and respectability, arguing that the latter acted not only as the imperative through which settler populations granted respect to Aboriginal people, but also came to represent for Aboriginal people, a value they claimed for themselves:

They saw themselves as respectable members of Australian society respectable in the same way that many other people were respectable: hardworking, well-spoken, well-dressed, clean-living. They demanded that their Aboriginal descent not be the basis for non-Indigenous people to deny them due respect.

Rowse (2005, p. 66) draws on statements from people of both cultures across the 1900-1970 timeframe to suggest that 'an abiding binary...respectable/rough' came to be applied as a mode of governance and self-governance. Aboriginal parents taught their children to be respectable rather than rough. They taught them to respect the settler families and in many ways to see themselves through settler eyes. Respectability became the way to open doors to valued resources of settler society. It 
is easy to see how in some very small remote settlements, respectability became a significant measure for determining life chances within and between cultures.

This trajectory of self-governance within settler norms, of course, had great costs for Aboriginal people, including hurts and tensions that continue to play out within and between families. People do articulate this, but they also appreciate the benefits of staying on country whilst ensuring their children are equipped for the contemporary world. The next section, drawn again from local accounts, suggests the strengthening of path dependence between these groups in Western Queensland.

\section{Equal Pay, Changes in the Cattle Industry and a New Era}

Across Australia, Aboriginal stockmen were vital to the cattle industry, and whole families organised their lives around it, however this came to a slow end in the late 1960s and through the 1970s. The introduction of equal pay legislation for Aboriginal workers coincided with a modernising of the labour structure and, across Australia, many stockmen lost their jobs. Commenting recently on this significant turning point in colonial relations, the introduction of equal pay, productivity commissioner Gary Banks (2009, p. 6) said:

Despite warnings by some at the time, this apparently well-motivated action led to the majority losing their jobs, driving them and their extended families into the townships - ultimately subjecting them to the ravages of passive welfare, with liberalised access to alcohol as the final blow. Good intentions, bad consequences, very, very difficult to remedy.

In Diamantina Shire many Aboriginal people already employed in the cattle industry stayed on until they retired. Nevertheless the shift meant no jobs for young people. Local Aboriginal people said:

We could not be unemployed, could not be a bludger! Everyone has to work!

And settler families said:

We could not let one group in the community become unemployed in any long term way. That would lead to a situation we would not want to live with.

Not long after the Equal Wage case and with Aboriginal unemployment rising across the country, the Federal government introduced the Community Development Employment Program (CDEP). This program offered funding for organisations to create part time employment for Aboriginal people in return for social security payments. This option was considered briefly and rejected by the Diamantina community. In preference, the community sought an avenue to permanent full time employment that would be available to anyone in the community.

In a stroke of entrepreneurial initiative, Diamantina Shire Council provided the alternative employment to compensate for disappearing cattle jobs. By turning its core functions of roads and works into a business, investing in construction equipment, and through careful use of grants and contracts, council built the expertise to undertake even significant construction projects, such as airport upgrades. Having heavy machinery in the area, council is inevitably the best situated contractor for remote work. So in this regard, remoteness has been employed as a resource. Roads 
are improved which increases tourism and facilitates movement of stock, the shire's assets are increased, the capabilities and human resources of the shire are built and the local economy is strengthened. Between roads and administration council is able to employ about 80 people, more than half of whom are Aboriginal.

This significant event sets Diamantina apart from many remote shires, because no gap was created in Aboriginal employment. The contribution of Aboriginal people to the shire's labour force was recognised. People who were in the pattern of full time work stayed in that pattern. New opportunities for training and certification opened up, and those difficult to remedy circumstances referred to by Gary Banks, that created such a devastating turning point in many settlements, were avoided in this shire. The link between relationships, respect and economic participation was strengthened.

\section{A Different Cultural Symbolic}

Aboriginal people hold the above stories alongside a parallel version of events. They acknowledge Aboriginal people are accepted, but Aboriginal culture is not. Inclusion has hitherto meant inclusion in the settler way of life, rather than inclusion in a whole that is bigger than both cultural groups.

Wangkangurru/Yarluyandi People say that they have made significant cultural shifts. They learned to live the settler way, speak settler language, engage with Christianity, and observe Christian holidays. They do wonder why so little interest has been shown in their culture, why so few settler families appreciate the significance of Aboriginal Law of Land and related stories and ceremonial life, why there is so little interest in the pre-settler history of the area, or of their part in history since European settlement. They grieve loss of cultural expression and recognise the cost of this in terms of broken cycles of ritual life, loss of language, haltering transmission of culture to the young, internalised tensions in and between families and continuing impact of colonisation on mental well being. Aboriginal people have clearly expressed leadership that has gone unrecognised. For example, Aboriginal Elders with vision led their families in a transformation of daily practices to secure the respect of the settlers. Significant Aboriginal leadership in pursuing knowledge of Aboriginal life in the Simpson Desert, has attracted more interest and recognition from scholars elsewhere than from local people.

Native Title legislation seemed to promise some redress of the imbalance. However, here, as elsewhere across Australia, negotiations have been lengthy, remain unresolved and have added to tensions locally, rather than contributing to social cohesion. There have however been some significant and timely gains. Anthropologists and linguists associated with the Native Title research have shown strong interest in culture, language and the long association with place. This has occurred whilst there are still some people alive who were born in the desert, spent their growing years there and who remember well the rhythms, practices, songs, stories and language of their Country. This has satisfied some of the desire for recognition that has not been forthcoming locally, and facilitated some unleashing of the constraints around expressing culture.

The appointment of a Wangkangurru person as National Parks manager has provided opportunity both for a more tangible expression of caring for country and a focused effort around retracing the paths of the Ancestors and depicting these in locally visible sites and artworks. Council, encouraged by an Aboriginal Councillor, 
has responded by working more closely with Traditional Owners around Native Title and cultural heritage sites, particularly as they are impacted by road construction and maintenance. Council has also become more conscious of ensuring that there are funds and support for celebrating days of significance to Aboriginal people and encouraging Aboriginal guests and celebrities to visit town.

\section{Discussion}

Altman (2009) asks why it is that policy cannot embrace diversity. Is it, he asks, that mainstream society still wants to wipe out Aboriginal culture, or that policy can only ever be technicist, or that Aboriginal and Torres Strait Islander culture is perceived as a threat to neoliberal markets? This section considers what can be drawn from the case study to speak to these questions.

Firstly, the case study exemplifies the blueprint held by mainstream Australia for relations between Aboriginal and settler people. The imperative is 'conform or else'. This is the voice of settler Australia, and is the continuing colonising project. In a million large and small ways this is the message to Aboriginal and Torres Strait Island people, wherever they live. This message is now unspoken, but still heard between residents in the small settlements of the case study site. It is carried in by government service delivery personnel, it is echoed through media and it underpins broader policy messages. The politicised Northern Territory intervention and the 'Closing the Gap' campaign amplify this as a dominant message from the broader Australian community to first Australians. Despite the apology, there is still no other consistent policy message. The Council of the case study site now has its ears open for new ways, but the messages from its environment are skin deep overlays about embracing diversity that barely conceal this other imperative. This is the great poverty of policy, including 'closing the gap' and 'social inclusion'. They provide no vision and no leadership about how cultures shall live together, except in conformity, no vision for government personnel to take into remote communities to guide their practice, no vision for remote governments to operate by.

Throughout this paper, I have emphasised the agency and leadership of Aboriginal people in the case study site. Listening to their story, one recognises immediately the tough implications of the decision they made and the determination it has taken to carry that decision through in everyday living for over a hundred years. This incurred, not only living the white way, but also living for the most part on the lower rungs of the white social hierarchies - working on stations you will never own, cleaning other people's houses. This is now changing - one earns one's place at higher rungs of the ladder. Yet, there are wounds from this choice. Local people observe however, when traversing remote areas and encountering Aboriginal groups who have positioned themselves as outsiders, that the outsider position is even more harmful to oneself, one's culture and one's children. It comes back to the children, and wanting them to have mobilities in both worlds.

Settler society relies on the self-governance of individuals within certain norms, and both government and community react where groups resist such norms. The Aboriginal people of this area have become adept at self-governance in settler terms. This is a huge relief to the settlers. Yet, the case study also illustrates that selfgovernance for Aboriginal people, as for all of us, is attached to respectful relations, genuine opportunities and fulfilling lifeworlds. For the most part, in Diamantina Shire, Aboriginal people have had this access to social and economic goods. If we 
suspend temporarily the notion that cultural symbolics are mutually exclusive, it becomes evident in the case study accounts, that people are active in more than one symbolic. People are constantly engaged in projects: trips to the desert, walking the old tracks, recording the old folks, gathering medicinal herbs, enjoying the bird and plant life that follow the floods, painting stories and sites of significance, engaging with anthropologists and archaeologists, and inputting on culture in schools. Place, country, culture exert an alternative shaping force to that of socioeconomic systems and structures (de Certeau, 1984, Rose, 1996; Walker, 2007). Sadness at what is lost continues, as does regret that this lifeworld must be covertly enjoyed, but local people do claim that the stable infrastructure that supports their socioeconomic lives also provides the space to sustain rich lifeworlds. Aboriginal people are implicated in the local reproduction of settler norms, yet privately maintain a parallel lifeworld commitment to their own culture. As they now try to make their culture more visible, they do so in the context of valued relations. These are all difficult tensions to hold, and insensitive external intervention could cut across them badly.

Local government in remote areas presents enormous challenges. It bridges the multiple dimensions between external layers of government that have power, resources, and agendas that stem from their more numerous and vocal urban and coastal constituents and the aspirations of local people who, themselves, are holding together a complex historical, political, socioeconomic and environmental nexus. Remote local government is best served by relations to other levels of government that are informed by the principle of subsidiarity. In other words higher levels of government recognise that the local, especially the remote local, is best situated to hold together and govern, local affairs. This is not an argument in support of insularity, but rather in support of ongoing dialogical, reflexive, supportive and responsive relations between governments, both horizontally across localities and regions, and vertically from local, through state to federal. Diamantina Shire is strategically led by long term locals. They hold firm relations with state and federal governments, and horizontally to local shires and networks. Their ability to read both the local politics and agendas and the external ones, and to forge links between them that bring some benefit to both, is pivotal to local well being. Like most shires, Diamantina contracts in a Chief Executive Officer (CEO), and this is a vital operational role, as well as a bridging one to public sector governance and ethics. Yet, the strategic role of locals is irreplaceable, and one which must be nurtured by both CEO and external levels of government. It is locals, through long term relations, who hold the commitment to everyone living as equals, and it is through the local, civic, process that Aboriginal people are beginning to make their culture visible. A recent intent of Queensland government to force local government amalgamations across the State was successfully fought by western shires. Tensions being worked with locally, would collapse in the face of forced amalgamation. The state government, with no awareness of what damage it could cause, would have no means or capacity to redress the harm. A newly created shire could set this process back to where it was many decades ago. I labour this point, not because state and federal governments are making mistakes in the application of subsidiarity, but because there is no clearly articulated commitment to it or agreed principles and protocols for the practice of it. As remoteFocus (2008) indicates, this suggests a lack of coherent vision for remote governance, and as Altman (2009) infers, this strips government interventions to technicist minimalism.

It must be acknowledged that this circular interdependence of settler norms, respect and relationships as a basis for securing and sustaining services and therefore 
enabling rights in remote settlements signals the governmental and oppressive dimensions of social inclusion. Rights become dependent on the kinds of selfresponsibilisation that are required to make liberal governance work at a distance. Rights are doubly compromised here; they rely on the relationship Aboriginal people can establish to the local or regional governing agency and its capacity to sustainably secure services in remote areas; further, they rely on the adoption by Aboriginal people of certain modes of self-responsibilisation that may be at odds with their culture.

Altman (2009) implies that the desire of settler governments and communities to control Aboriginal people might have some relation to them being a threat to global markets. Aboriginal people in Queensland do not own large tracts of land and are not well positioned to interrupt or make demands on companies seeking to extract resources. Nevertheless, it can be seen from the case study that small remote communities are not well positioned to benefit from harvesting of local resources. Even the cattle industry, whilst profitable to the national economy, now operates across space, with little return to the local economy. In this sense, remote settlements would do well to agitate for increased connectivity between local stocks and flows. It would be difficult for governments to pin pastoral corporations down to a percentage local return on local consumption (grasses, water, roads) yet this is an area of conflict between local and national interests where even small regulatory adjustments could make a difference. There is another way in which Aboriginal people might be a threat to global capitalism, and that is in lack of dependence on global markets. If most of us, believing ourselves to be exercising freedom of choice, are actually governable through our pursuit of market goods, including finance, superannuation, private health insurance, material and lifestyle goods (Rose, 1999), then remote Aboriginal people have positioned themselves largely beyond this regulatory force. Some, it is true, have been caught in its shadow (alcohol, substance abuse), but for the majority, the market is not the main mechanism of governance and/or freedom.

There is then some truth in each of Altman's three conjectured rationales for present policy. In the absence of a coherent vision for cultural recognition, we can assume that government and community still want Aboriginal culture to disappear in anything but its most superficial of guises. In the absence of a coherent articulation of subsidiarity, government intervention is technicist. Given that, governance in advanced liberal societies relies on people being closely hooked to market dependence, and thereby conferring enormous freedoms to market mechanisms, then Aboriginal people, if not a threat to global capitalism, pose a significant challenge to governments of market-centric states.

\section{Conclusion}

This valuable glimpse into the life of a community spotlights the enormity of trying to bring about change through strategies that rely predominantly on government service delivery by external agents. National and state policy, particularly in the media spotlight, impose short timeframes and seek swift outcomes, but the case study suggests outcomes depend on social dynamics and path dependencies that have developed slowly, over time in the particular geographical locale. People inevitably build upon, rather than act outside of, their own legacies, and this is too rarely recognized as the starting point in the process of external policy intervention in settlements. 
Throughout the case study, it has been evident that disciplinary strategies are at work, exhorting particular modes of self-governance of people across cultures. Such imperatives also characterise the contemporary policy domain. In the local site, the required style of self-governance is rewarded with long-term, face-to-face, respectful relations and with access to social and economic benefits and opportunities, including the opportunity for political office. Sustained over many decades, these reciprocities are well regarded. It is difficult to see that the policy domain has any mechanism for providing such a balance to the governmental imperative. Where the historical legacy involves poor access to services, poor relations to government, resistance to assimilation, and scant local infrastructure to build upon, then the road ahead is difficult indeed.

No starting point for any new or renewed intervention is a blank slate; rather each intersection of local people and the state is inescapably shaped by all that has gone before. If both are not held within the policy gaze, then a familiar and unjust binary is reinstated, and valuable opportunities for learning are lost. At this threshold point negotiations need to proceed with care, historical trajectories need to be recognised, local authority over local affairs respected, indeed nurtured, and relationships need to be held for the long haul. It is hard to see how this has any chance of happening outside of a clear and articulate theoretical framework that itself becomes subject to reflection. The continuing presence of two cultural symbolics, despite two centuries of disciplinary regulation, is a source of hope. It is not the answer to the dilemma of rights and relationship, but provides a glimpse of emancipatory possibility in an otherwise oppressive field. It would be good to see a more explicit articulation of a framework at government levels that indicates that we have learned from the past, that we are in relationship for the long haul, that we acknowledge obligation, that we are deconstructing our familiar biases, that we are dealing with our fear of cultural difference, that we are realigning priorities for public investment in a more substantial way, that we understand subsidiarity, and are capable of making policy based on the realities of remote life.

\section{Acknowledgement}

The author wishes to thank the Wangkangurru/Yarluyandi people for their guidance in the research informing this paper, and Diamantina Shire and settler families for their input. Thanks also to Colleen Wall. I hope that I have justly reflected the emphases of all that you have shared with me.

The work reported in this publication was supported by funding from the Australian Government Cooperative Research Centres Programme through the Desert Knowledge Cooperative Research Centre. The views expressed do not necessarily represent the views of Desert Knowledge CRC or its participants.

\section{Note}

${ }^{1}$ I use the term Aboriginal when speaking of desert people. I use the term settler to refer to non Aboriginal people of desert towns. In broader references, I use Aboriginal and Torres Strait Islander People unless referring to sources that use the term Indigenous. 


\section{References}

Altman, J.C. (2009). Beyond closing the gap: Valuing diversity in Indigenous Australia. (Working Paper No 54/2009). Canberra, Australian Capital Territory: Australian National University, Centre for Aboriginal Economic Policy Research.

Altman, J., Biddle, N. and Hunter, B.H. (2005). A historical perspective on Indigenous socioeconomic outcomes, 1971-2001. Australian Economic History Review, 45 (3), 273-9.

Altman, J. C., Biddle, N. \& Hunter, B.H. (2008). How realistic are the prospects for "closing the gap" in socioeconomic outcomes for Indigenous Australians? (Discussion Paper No 287/2008). Canberra, Australian Capital Territory : Australian National University, Centre for Aboriginal Economic Policy Research.

Australian Bureau of Statistics (2007). 2006 Census of Population and Housing. Quickstats for Diamantina LGA, Barcoo LGA, Boulia LGA, Winton, LGA, Mt Isa LGA, Queensland State. Retrieved November 13, 2007 from www.abs.gov.au

Australian Bureau of Statistics (2008). 2006 Census of Population and Housing. Community Profile Indigenous Population, for Diamantina LGA, Boulia LGA, Queensland State. Retrieved August 13, 2008 from www.abs.gov.au

Banks, G. (2009). Evidence-based policy-making: What is it? How do we get it? ANZSOG/ANU Public Lecture Series, Canberra. Retrieved September 25, 2009 from http://www.pc.gov.au/speeches/cs20090204

Behrendt, L. (2008). 'The long path to reconciliation'. In H. Sykes (Ed.). Issues of our time, pp. 22-33. Albert Park: Future Leaders.

Commonwealth of Australia (2010). Social Inclusion Unit - Overview. Retrieved January 21, 2010 from http://www.socialinclusion.gov.au/ Pages/Overview.aspx

de Certeau, M. (1984). The Practice of the everyday. Berkeley: University of California.

Dillon, M. \& Westbury, N. (2007). Beyond humbug: transforming government engagement with Indigenous Australia. Westlakes, S.A.: Seaview Press.

Dodson, M. (2009). Address to the National Press Club. February, 2009. Retrieved November 29, 2009 from http://www.reconciliation.org.au/home/latest/mickdodson-speaks-at-the-national-press-club

Foucault, M. (1984). 'Space, knowledge and power'. In P. Rabinow (Ed.), The Foucault reader (pp. 239-256). Harmondsworth: Penguin.

Foucault, M. (1991). 'Governmentality'. In G. Burchill, C. Gordon and P. Miller (Eds). The Foucault effect: Studies in Governmentality (pp. 87-104). Hemel Hempstead: Harvester Wheatsheaf.

Ingamells, A., Holcombe, S. and Buultjens, J. (2010). 'Economic development and remote desert settlements’. Community Development Journal Advance Access published on February 21, 2010; doi:10.1093/cdj/bsq012

Lukin Watson, P. (1998). Frontier lands \& pioneer legends: How pastoralists gained Karuwali land. St Leonards: Allen \& Unwin.

McGrath, A. (1987). Born in the cattle. Sydney: Allen \& Unwin.

Nolan, C. (2003). Sand hills and channel country. Bedourie: Diamantina Shire Council. 
Pearson, N, (2009). Countdown to close the education gap. The Weekend Australian, 21-22 February, 2009. Retrieved November 30, 2009 from http://www.theaustralian.com.au/news/opinion/countdown-to-close-educationgap/story-e6frg786-1111118915700

Pholi, K., Black, D. \& Richards, C. (2009). 'Is ‘Close the Gap’ a useful approach to improving the health and wellbeing of Indigenous Australians?' Australian Review of Public Affairs, 9(2), 1-13.

Read, P. (2000). Belonging: Australians, place and Aboriginal ownership. Cambridge: Cambridge University Press.

remoteFOCUS (2008). Prospectus: remoteFOCUS: Revitalising remote Australia. Retrieved January 15, 2010 from http://www.desertknowledge.com.au/dka/ documents/remoteFOCUS\%20Propsectus\%20\%20additional\%20information \%20FINAL\%20RELEASE\%20(2).pdf

Rose, D. B. (1996). Nourishing terrains. Canberra: Australian Heritage Commission.

Rose, N. (1999). Powers of freedom: Reframing political thought. Cambridge: Cambridge University Press.

Rowse, T. (2005). 'Aboriginal respectability'. In T. Rowse, (Ed.). Contesting assimilation (pp. 49-67). Perth, W.A. API Network: Curtin University of Technology, Australian Research Institute.

Rowse, T. (2006). 'Towards a history of Indigenous statistics in Australia'. In NATSISS, Assessing the evidence on Indigenous socioeconomic outcomes: A focus on 2002. NATSISSS, Research Monograph 26. Canberra: Australian National University, Centre for Aboriginal Economic Policy Research.

Rudd, K. (2009). Letter to Productivity Commission re terms of reference for the Overcoming Indigenous Disadvantage (OID) Report. In SCRGSP (Steering Committee for the Review of Government Service Provision) 2009, Overcoming Indigenous Disadvantage: Key Indicators 2009, Canberra: Productivity Commission.

SCRGSP (Steering Committee for the Review of Government Service Provision) (2009). Overcoming indigenous disadvantage: Key indicators 2009, Canberra: Productivity Commission.

Smith, D.E. \& Hunt, J. (2005). Strengthening Indigenous community governance; a step towards advancing Reconciliation in Australia. (Topical Issues 4/2005). Canberra: Australian National University, Centre for Aboriginal Economic Policy Research.

Stafford Smith, M (2008). 'The 'desert syndrome'- causally-linked factors that characterise outback Australia'. The Rangeland Journal, 30 (1), 3-14.

Stafford Smith, M. Moran, M. \& Seemann, K. (2008). 'The 'viability' and resilience of communities and settlements in desert Australia'. The Rangeland Journal 30 (1), 123-135.

Walker, R.C. (2007). 'An alternative construction of identity: A study of place based identity and its implications'. American Journal of Communication, 9 (3), Retrieved 23/10/2009 from. http://acjournal.org/holdings/vol9/fall/

Watson, V. (2009). 'From 'The Quiet Revolution' to 'Crisis' in Australian Indigenous affairs’. Cultural Studies Review 15(1), 88-109. 


\section{Biographical Note}

Ann Ingamells teaches in the School of Human Services and Social Work at Griffith University. With research and teaching interests in community development, Ann has contributed to the research programs of Desert Knowledge CRC, and is an active contributor to Community Development Queensland. 